\title{
Study of the Effect of Food Habit, Lifestyle and Daily Trip on Physical and Mental Status of Subjects at Islamic University in Kushtia, Bangladesh*
}

\author{
Shahedur Rahman ${ }^{1}$, Anowar Khasru Parvez ${ }^{2 \#}$, Abdus Sabur ${ }^{3}$, Shahjahan $\mathrm{Ali}^{3}$ \\ ${ }^{1}$ Department of Genetic Engineering and Biotechnology, Jessore Science and Technology University, Jessore, Bangladesh \\ ${ }^{2}$ Department of Microbiology, Jahangirnagar University, Dhaka, Bangladesh \\ ${ }^{3}$ Department of Accounting and Information Systems, Islamic University, Kushtia, Bangladesh \\ Email: "khasru1973@yahoo.com
}

Received November 20, 2011; revised December 25, 2011; accepted January 10, 2012

\begin{abstract}
This is a qualitative (study that used framework analysis) to examine by interviews among University personnel who live inside and outside the Islamic University campus in Kushtia, Bangladesh. In the present study, we found that subjects who live inside of the University feel better physically and mentally than the nonresident subjects. It was found that residents are more fit and feel better during and after class time. Resident subjects have less stress and maintain balanced diet for which they have good average BMI value than the nonresident subjects. In addition nonresident subjects have suffered diseases comparatively much more than resident subjects.
\end{abstract}

Keywords: Food Habit; Life Style; Daily Trip; Physical Health; Mental Health; Health Risk

\section{Introduction}

A person's life style, mental health and physical health are closely related. They often affect one another. Recent research on psycho physiology revealed that some mental health problems/mental stress conditions can cause physical ailments. Lifestyle factors, mental and physical stress, food habit etc can also influence the onset and progression of various diseases like cancer, cardiovascular disease, diabetes mellitus (type 1 \& type 2), [1] infectious disease [2], myocardial ischaemia [3], cell aging [4], inherited long QT syndrome, coronary heart disease [4], mutation in DNA sequence, immune system disorders and other problems. Some time the use of psychological techniques can even reduce the risk of these most major diseases [4].

Increasing evidence suggests that diet and lifestyle in childhood and adolescence also have a potential lifelong effect on risks for many chronic diseases. The risk for diabetes was almost 2-fold higher in subjects aged $>40$ compared with the age group 20 - 30, systolic BP > 140 $\mathrm{mm} \mathrm{Hg}$, and waist hip ratio (WHR) for men. Significant association of BMI and type 2 diabetes was also observed for females. BMI > 30 showed to be exceedingly risky state for the occurrence of diabetes $[5,6]$.

\footnotetext{
"The authors declare that they have no competing interests.

"Corresponding author.
}

Since there have been very few studies on this issue in Asian countries, the present questionnaire survey was elucidated to investigate the relationship between food habit, various stressful life events and disease onset and prognosis in a community of a public University of Bangladesh. Islamic University, Kushtia is situated on the boundary between two districts Kushtia and Jhenaidah. It is $24.5 \mathrm{~km}$ away from Kushtia town, $23.5 \mathrm{~km}$ away from Jhenaidah town and $15 \mathrm{~km}$ away from Shailkupa. Every day students, teachers, and staffs are transported from these three towns who reside there, to the University campus. And after that time they are transported back to their resident by the University bus. This daily trip can cause mental and physical stress to a person. There are six halls for students (four for males and two for females) in university campus. Their capacity is approximately 2200. There are 7 quarters for teachers and staff, a dorm for teacher in University campus. The teacher, staff and student who stay in campus generally do not need to travel daily to Kushtia, Jhenaidah or Shailkupa. There, it is reasonable to assume they do not have same kind of stress than others. There is a small group of student and staff who neither live inside University campus nor Kushtia, Jhenaidah or Shailkupa. They live within $1 \mathrm{~km}$ of area from campus and they have different mode of transportation. In the present study, we aimed to find the effect of food habit, lifestyle 
and daily trip on physical and mental status among the subjects who live inside the campus and outside the campus.

\section{Methods}

\subsection{Study Subjects}

This is a qualitative study that used framework analysis to examine interviews among University personnel including teacher, student, and staff. The study comprised 208 subjects (184 students, 17 staffs, 7 teachers). Among them 112 were male and 96 were female. The subjects were randomly chosen. All participants were interviewed by using standard questionnaires that evaluated lifestyle habits, food habits, trip habit, clinical and biological characteristics, etc. In this work, we included 160 smokers and 45 nonsmokers. To join the study, the participant had to sign a written informed consent (there they all agree about publishing the study result). Because the study simulates the usual practice in University in Bangladesh, an ethical approval was not necessary.

\subsection{Statistical Analysis}

The number of enrolled participants was found to be adequate to evaluate two-sided standardized differences between the subgroups of the study. Dietary assessment/ food intake variables, socio-demographic and lifestyle variables, anthropometric, clinical and biochemical characteristics (BMI), physical activity variables, trip variables and stamina variables are presented in absolute and relative frequencies. Associations between categorical variables were evaluated by means Pearson's correlation test, while differences between categorical and several biochemical, clinical and nutritional variables were evaluated, i.e. standardized residuals against fitted values. All reported p-values are based on two-sided tests and compared to a significance level of 0.05 and 0.01. SPSS 10 (SPSS Inc., Chicago, IL, USA) software was used for all the statistical calculations.

\section{Results}

From Table 1, it is evident that nonresident subjects do more physical exercise then resident person. It is observed that the resident subjects have higher percentage of normal BMI than nonresident person. On the other hand, nonresident people are either more over weight or underweight than resident subjects. There is a significant correlation between nonresident and resident personnel's BMI (0.230 at 0.05 level). So the correlation proves that there is good relationship between residence and BMI.

It is clear that nonresident subjects suffer from different diseases than resident subjects. They also suffered higher rates of hereditary disease, skin disease, blood
Table 1. Comparison between various stress variable between nonresident and resident subjects.

\begin{tabular}{|c|c|c|c|}
\hline \multicolumn{2}{|c|}{ Parameters } & \multirow{2}{*}{$\begin{array}{c}\text { Nonresident } \\
29.36 \%\end{array}$} & \multirow{2}{*}{$\begin{array}{l}\text { Resident } \\
36.58 \%\end{array}$} \\
\hline Physical exercise & No exercise & & \\
\hline & Walk & $40.5 \%$ & $39 \%$ \\
\hline & Game & $17.46 \%$ & $14.63 \%$ \\
\hline & Others & $5.6 \%$ & $6.1 \%$ \\
\hline & Walk \& game & $4.8 \%$ & $2.4 \%$ \\
\hline & Walk \& other & $2.4 \%$ & $1.2 \%$ \\
\hline \multirow[t]{4}{*}{ BMI } & Unknown & $1.6 \%$ & $1.2 \%$ \\
\hline & Under weight & $15.1 \%$ & $8.5 \%$ \\
\hline & Normal & $68.3 \%$ & $85.4 \%$ \\
\hline & Over weight & $15.1 \%$ & $4.9 \%$ \\
\hline \multirow[t]{9}{*}{ Disease } & Hereditary & $3.2 \%$ & - \\
\hline & Environmental & $4.8 \%$ & $1.22 \%$ \\
\hline & Skin & $8 \%$ & $6.1 \%$ \\
\hline & Blood related & $0.8 \%$ & - \\
\hline & Food born & $0.8 \%$ & $2.44 \%$ \\
\hline & Water born & $0.8 \%$ & $3.7 \%$ \\
\hline & Mix & $4 \%$ & $1.2 \%$ \\
\hline & Others & $8.7 \%$ & $9.8 \%$ \\
\hline & No disease & $69 \%$ & $75.6 \%$ \\
\hline \multirow{7}{*}{$\begin{array}{l}\text { Food habit } \\
\text { pattern }\end{array}$} & Meat & $43.9 \%$ & $38.9 \%$ \\
\hline & Red meat & $19.5 \%$ & $20.6 \%$ \\
\hline & White meat & $4.9 \%$ & $8.7 \%$ \\
\hline & Fish & $19.5 \%$ & $24.6 .55 \%$ \\
\hline & Vegetables & $41.5 \%$ & $31 \%$ \\
\hline & Fruits & $25.6 \%$ & $26.2 \%$ \\
\hline & Mix & $29.3 \%$ & $39.7 \%$ \\
\hline \multirow[t]{7}{*}{ Study time } & 1 (hour) & $2.4 \%$ & $4.8 \%$ \\
\hline & 2 (hours) & $19.5 \%$ & $21.4 \%$ \\
\hline & 3 (hours) & $19.5 \%$ & $18.3 \%$ \\
\hline & 4 (hours) & $25.66 \%$ & $20.6 \%$ \\
\hline & 5 (hours) & $7.32 \%$ & $7.1 \%$ \\
\hline & 6 (hours) & $8.5 \%$ & $11.9 \%$ \\
\hline & $6<$ (hours) & $12.2 \%$ & $3.19 \%$ \\
\hline \multirow[t]{2}{*}{ Balance diet } & Yes & $55.55 \%$ & $59.75 \%$ \\
\hline & No & $44.44 \%$ & $40.24 \%$ \\
\hline \multirow[t]{4}{*}{ Sleeping habit } & Sleep before 12 a.m. & $37.30 \%$ & $29.26 \%$ \\
\hline & Sleep after 12 a.m. & $62.69 \%$ & $70.73 \%$ \\
\hline & Wake up before 7 a.m. & $73.01 \%$ & $57.31 \%$ \\
\hline & Wake up after 7 a.m. & $25.39 \%$ & $41.46 \%$ \\
\hline
\end{tabular}

related disease and other disease. Though resident subjects have higher rate of food born and waterborne diseases. Table 1 show that there is no significant differ- 
ence in food habit between resident and nonresident subjects with respect to meat and fish consumption. But in case of mix food resident subjects like it more than the nonresident subjects. On the other hand, higher percentage of resident person studies more than six hours. This data shows that more resident subjects maintain balanced diet then than the nonresident subjects.

Table 1 illustrates the sleeping habit pattern of resident and nonresident subjects. The data shows higher percentages of nonresident person go to bed early than resident person. The data shows that higher percentage of nonresident persons wake up early in the morning then the resident person. There is significant correlation present between residence and wake up time at 0.05 levels $(-0.164)$. Significant correlation also present between residence and bed time. It is found that there is good relationship between residence and wake up time $(-0.164$ at 0.05 level), residence and bed time (0.238 at 0.01 level) (Table 2).

Figure 1 shows the relationship between resident and nonresident subject's mental and physical feelings just after coming to campus and in classroom. Resident person physically and mentally feel better than the nonresident person during and after class hour. It is found that there is good relationship between residence and physical feelings (0.145 at 0.05 level), residence and mental feelings (0.298 at 0.01 level).

Table 3 indicates that selected independent variables explain 35 percent variations in stress. All the independent variables are significant at 0 percent level of significance. The highest contributions for reducing stress are exercise, income and balanced diet as per primary data. It is to be noted that there is no multicollinearity among the independent variables since the range of VIF are from the lowest of 1.022 to the highest of 1.065. It is observed that 65 percent stress determined by the other variables, which are not considered in our analysis.

\section{Discussion}

Many studies show that poor physical health outcomes

Table 2. Correlations between sleeping time and residence.

\begin{tabular}{clccc}
\hline & & Residence & $\begin{array}{c}\text { Wakeup } \\
\text { time }\end{array}$ & $\begin{array}{c}\text { Bed } \\
\text { time }\end{array}$ \\
\hline Residence & Pearson Correlation & 1.000 & $-0.164\left(^{*}\right)$ & -0.083 \\
& Sig. (2-tailed) & 0.0 & 0.018 & 0.234 \\
& $\mathrm{~N}$ & 208 & 208 & 208 \\
Wakeup time & Pearson Correlation & $-0.164\left(^{*}\right)$ & 1.000 & $0.238\left(^{* *}\right)$ \\
& Sig. (2-tailed) & 0.018 & 0.0 & 0.001 \\
& $\mathrm{~N}$ & 208 & 208 & 208 \\
Bed time & Pearson Correlation & -0.083 & $0.238\left(^{* *}\right)$ & 1.000 \\
& Sig. (2-tailed) & 0.234 & 0.001 & 0.0 \\
& $\mathrm{~N}$ & 208 & 208 & 208 \\
\hline
\end{tabular}

"Correlation is significant at the 0.05 level (2-tailed); ${ }^{* *}$ Correlation is significant at the 0.01 level (2-tailed).

Table 3. Regression analysis (variables in the equation).

\begin{tabular}{lccccccc}
\hline \multicolumn{1}{c}{ Variables } & Beta & SE & Beta & t & Sig. Tolerance VIF \\
\hline Constant & -0.358 & 0.212 & & -1.687 & 0.093 & & \\
Balanced Diet & 0.244 & 0.057 & 0.249 & 4.259 & 0.000 & 0.939 & 1.065 \\
BMI & 0.183 & 0.065 & 0.163 & 2.840 & 0.005 & 0.967 & 1.034 \\
Exercise & 0.328 & 0.060 & 0.315 & 5.427 & 0.000 & 0.949 & 1.053 \\
Income & 0.387 & 0.080 & 0.276 & 4.825 & 0.000 & 0.977 & 1.023 \\
Disease & 0.193 & 0.062 & 0.179 & 3.128 & 0.002 & 0.978 & 1.022 \\
\hline
\end{tabular}

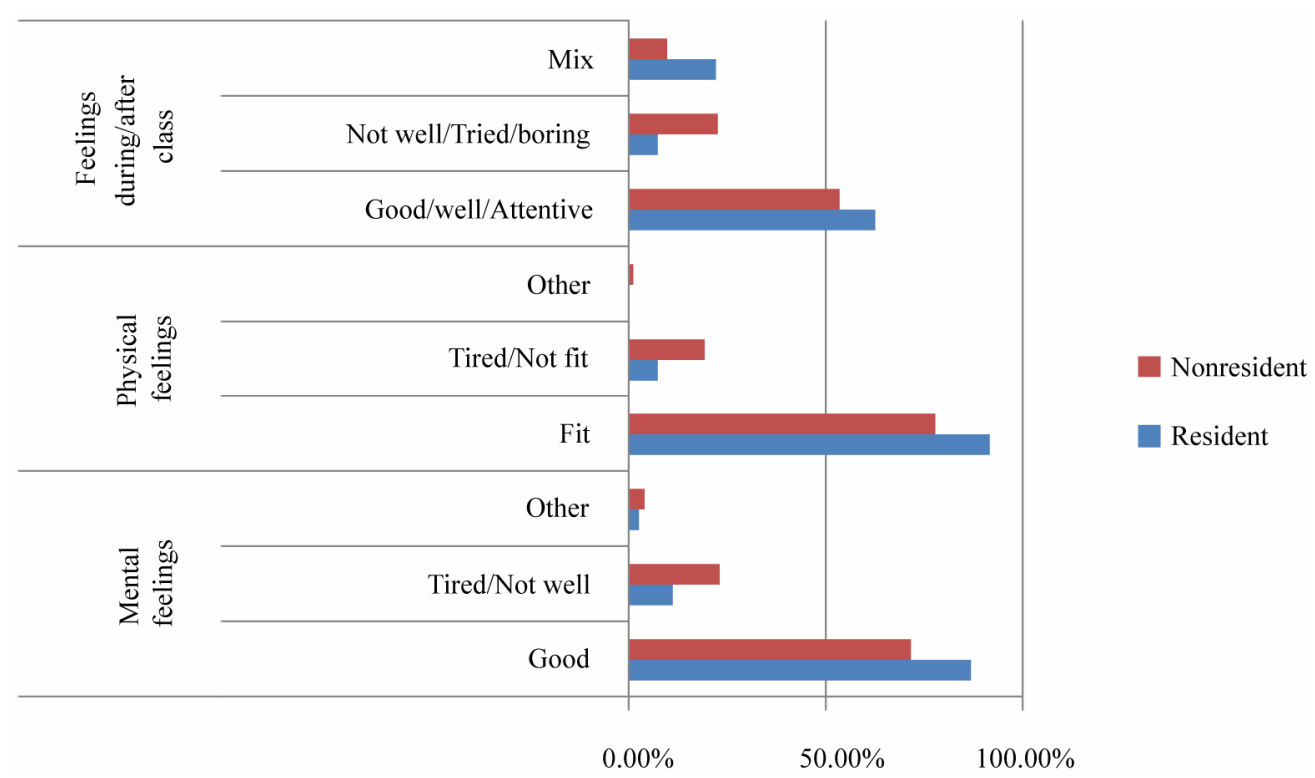

Figure 1. Mental and physical feelings just after coming to campus and in classroom. 
result from higher level of stress including blood pressure, hypertension [7,8], self-reported illness [9], immune function, diabetes, hyperglycemia [10], heart disease [11], dyslipidemia [12], preterm birth [13] and increased carotid artery intima-media thickness [14]. In addition, health damaging behaviours such as drug misuse [15] and cigarette smoking [16] have also been found to bear strong correlation with stress.

Poor mental health is also related to stress it include psychological distress [17], depression [18], reduced psychological well-being [19] and psychological functioning [20], poor mental health [21], increased anxiety [22], suicidal ideation [15] and reduced self-esteem.

Several of the studies specifically considered the effect of stress on the management of chronic diseases including hypertension [23], HIV/AIDS [24], sickle cell disease [25], mental illness [26], substance misuse problems [22] and myocardial infarction [11]. Elevated stress hormones contribute to the development of metabolic syndrome that in turn may be a risk factor for coronary heart disease and depression.

This study is a cross-sectional study that cannot provide causal relationships but can only be suggestive of future research. The evaluation was ascertained through a questionnaire. We cannot exclude the possibility of under-reporting or over-reporting, although subjects completed the questionnaires with the help and supervision of well-trained staff. Further evaluation could increase the accuracy of our findings. Also, because of a high degree of statistical co-linearity, ability to distinguish the effects of our subjects was limited. In addition, a limited variation in intakes of meat, fish, milk, etc. in our subjects could lead to insufficient statistical power to detect significant associations.

From this study it observed that the person who lives within the campus goes to bed late and at the same time they wake up late at the morning then their nonresident counterparts. Because of this resident subjects can spend more time to study at night. The data also shows that resident subjects spent less time doing physical exercise than the nonresident personnel. This data proves that the resident person spent more time for study.

Data also shows that there is not much difference in food habit between resident and nonresident subjects in case of meat and fish (protein). But in case of mixed food more resident subjects like it than the nonresidents because resident subjects experience monotony. And more resident subjects maintain balanced diet than the nonresident subjects. The comparison of BMI among resident and nonresident subjects also suggests the above information. BMI comparison shows that more resident person have their BMI range at normal level than the nonresident person, and the percentage of BMI range of nonresident person is higher in case of underweight and overweight.

The data also suggest that after traveling from Kushtia, Jhenaidah and Shailkupa higher percentage of nonresident subjects feel "tired" and "not well" both physically and mentally just after reaching University and during and after class. On the other hand, resident do not have to travel and much lower percentage of them feel "tired" and "not well" both physically and mentally. The data suggests that nonresident person have to bear more stress than the resident person. We also found in our study that the occurrence of disease is less frequent in resident person than the nonresident person. However, the prevalence of food and waterborne disease is grater among resident subjects than the nonresident subjects due to unhygienic conditions in hall dinning. Food cost of various income levels also varies. Students spent less money for their food compared to higher income level teachers and staffs.

It is concluded that nonresident person face more stress then the resident person. To deal with this stress maintain balanced diet, more physical exercise, hygienic practice may be helpful. On the other hand the University could be transformed to a fully residential university, because University is spending $\$ 1000$ - \$2000 every day for transporting students, teachers and staffs, but higher numbers of these nonresident subjects are under physical and mental stress due to the need to travel.

\section{Consent}

The study was performed with informed consent and following all the guidelines for experimental investigations required by the Institutional Research and Ethics Committee.

\section{Acknowledgements}

We thank Department of Biotechnology \& Genetic Engineering, Islamic University and the respondents who took part in the study.

\section{REFERENCES}

[1] K. Nakayama, K. Yamaguchi, S. Maruyama and K. Morimoto, “The Relationship of Lifestyle Factors, Personal Character, and Mental Health Status of Employees of a Major Japanese Electrical Manufacturer,” Environmental Health and Preventive Medicine, Vol. 5, No. 4, 2001, pp. 144-149. doi:10.1007/BF02918290

[2] S. Cohen and G. M. Williamson, "Stress and Infectious Disease in Humans," Psychological Bulletin, Vol. 109, No. 1, 1991, pp. 5-24. doi:10.1037/0033-2909.109.1.5

[3] P. C. Strike and A. Steptoe, "Systematic Review of Mental Stress-Induced Myocardial Ischaemia," European Heart Journal, Vol. 24, No. 8, 2003, pp. 690-693. doi:10.1016/S0195-668X(02)00615-2 
[4] M. Bambling, "Mind, Body and Heart: Psychotherapy and the Relationship between Mental and Physical Health,” Psychoter in Austerilia, Vol. 12, 2006, pp. 5259.

[5] A. Hussain, S. Vaaler, M. A. Sayeed, H. Mahtab, S. M. K. Ali and A. K. A. Khan, "Type 2 Diabetes and Impaired Fasting Blood Glucose in Rural Bangladesh: A Population Based Study," European Journal of Public Health, Vol. 17, No. 3, 2006, pp. 291-296. doi:10.1093/eurpub/ckl235

[6] Y. Paradies, "A Review of the Relationship between Psychosocial Stress and Chronic Disease for Indigenous and African American Peoples," Cooperative Centre for Aboriginal Health, Darwin, 2004.

[7] R. Corti, R. Hutter, J. Badimon and V. Fuster, "Evolving Concepts in the Triad of Atherosclerosis, Inflammation and Thrombosis," Journal of Thrombosis and Thrombolysis, Vol. 17, No. 1, 2004, pp. 35-44. doi:10.1023/B:THRO.0000036027.39353.70

[8] R. Din-Dzietham, W. N. Nembhard, R. Collins and S. K. Davis, "Perceived Stress Following Race-Based Discrimination at Work Is Associated with Hypertension in African-Americans. The Metro Atlanta Heart Disease Study, 1999-2001,” Social Science \& Medicine, Vol. 58, No. 3, 2004, pp. 449-461. doi:10.1016/S0277-9536(03)00211-9

[9] D. Williams and K. A. Lawler, "Stress and Illness in Low-Income Women: The Roles of Hardiness, John Henryism, and Race," Women Health, Vol. 32, No. 4, 2001, pp. 61-75. doi:10.1300/J013v32n04_04

[10] P. H. Skinner and D. Silverman-Peach, "Biabetes and Native Americans: Sociocultural Change, Stress and Coping," Native American Research and Training Center, 1989.

[11] M. A. Ong and T. Weeramanthri, "Stress and Worry Are Central Issues for Indigenous Heart Attack Survivors in the Northern Territory," Australian Journal of Primary Health, Vol. 8, No. 2, 2002, pp. 17-20. doi:10.1071/PY02021

[12] E. H. Johnson, P. Collier, P. Nazzaro and D. C. Gilbert, "Psychological and Physiological Predictors of Lipids in Black Males,” Journal of Behavioral Medicine, Vol. 15, No. 3, 1992, pp. 285-298. doi:10.1007/BF00845357

[13] N. Dole, D. A. Savitz, I. Hertz-Picciotto, A. M. Siega-Riz, M. J. McMahon and P. Buekens, "Maternal Stress and Preterm Birth,” American Journal of Epidemiology, Vol. 157, No. 1, 2003, pp. 14-24. doi:10.1093/aje/kwf176

[14] W. M. Troxel, K. A. Matthews, I. T. Bromberger and K. Sutton-Tyrrell, "Chronic Stress Burden, Discrimination, and Subclinical Cardiovascular Disease in African American and Caucasian Women,” Health Psychology, Vol. 22, 2003, pp. 300-309. doi:10.1037/0278-6133.22.3.300

[15] N. G. Dinges and Q. Duong-Tran, "Stressful Life Events and Co-Occurring Depression, Substance Abuse and Suicidality among American Indian and Alaska Native Ado- lescents," Culture, Medicine and Psychiatry, Vol. 16, No. 4, 1992, pp. 487-502.

[16] B. J. Guthrie, A. M. Young, D. R. Williams, C. J. Boyd and E. R. Kintner, “African American Girls’ Smoking Habits and Day-to-Day Experiences with Racial Discrimination,” Nursing Research, Vol. 51, No. 3, 2002, pp. 183-189. doi:10.1097/00006199-200205000-00007

[17] K. D. Lincoln, L. M. Chatters and R. J. Taylor, "Psychological Distress among Black and White Americans: Differential Effects of Social Support, Negative Interaction and Personal Control," Journal of Health and Social Behavior, Vol. 44, No. 3, 2003, pp. 390-407. doi:10.2307/1519786

[18] S. Gore and R. H. Aseltine, "Race and Ethnic Differences in Depressed Mood Following the Transition from High School," Journal of Health and Social Behavior, Vol. 44, No. 3, 2003, pp. 370-389. doi:10.2307/1519785

[19] C. Ellison, J. D. Boardman, D. R. Williams and J. S. Jackson, "Religious Involvement, Stress, and Mental Health: Findings from the 1995 Detroit Area Study," Social Forces, Vol. 80, No. 1, 2001, pp. 215-249. doi:10.1353/sof.2001.0063

[20] V. M. Murry, P. A. Brown, G. H. Brody, C. E. Cutrona and R. L. Simons, "Racial Discrimination as a Moderator of the Links among Stress, Maternal Psychological Functioning, and Family Relationships,” Journal of Marriage and Family, Vol. 63, No. 4, 2001, pp. 915-926. doi:10.1111/j.1741-3737.2001.00915.x

[21] S. O. Utsey, Y. A. Payne, E. S. Jackson and A. M. Jones, "Race-Related Stress, Quality of Life Indicators, and Life Satisfaction among Elderly African Americans,” Cultural Diversity \& Ethnic Minority Psychology, Vol. 8, No. 3, 2002, pp. 224-233. doi:10.1037/1099-9809.8.3.224

[22] S. O. Utsey and Y. A. Payne, "Psychological Impacts of Racism in a Clinical versus Normal Sample of African American Men,” Journal of African American Men, Vol. 5, 2000, pp. 57-72.

[23] H. S. Thompson, T. W. Kamarck and S. B. Manuck, "The Association between Racial Identity and Hypertension in African-American Adults: Elevated Resting and Ambulatory Blood Pressure as Outcomes,” Ethnicity and Disease, Vol. 12, 2002, pp. 20-28.

[24] S. Owens, "African American Women Living with HIV/ AIDS: Families as Sources of Support and of Stress," Social Work, Vol. 48, No. 2, 2003, pp. 163-171. doi:10.1093/sw/48.2.163

[25] R. J. Thompson, K. M. Gil, M. R. Abrams and G. Phillips, "Stress, Coping, and Psychological Adjustment of Adults with Sickle Cell Disease," Journal of Consulting and Clinical Psychology, Vol. 60, No. 3, 1992, pp. 433-440. doi:10.1037/0022-006X.60.3.433

[26] B. C. Ford, "Violence and Trauma: Predicting the Impact on the Well-Being of African American Women with Severe Mental Illness," Violence and Victims, Vol. 17, No. 2, 2002, pp. 219-232. doi:10.1891/vivi.17.2.219.33646 